\title{
Gender and geography : developments in the United Kingdom 1980-2006
}

Genre et Géographie : Les Développements en Grande-Bretagne, 1980-2006.

\section{Jo Little}

\section{(2) OpenEdition}

1 Journals

\section{Electronic version}

URL: http://journals.openedition.org/belgeo/11216

DOI: $10.4000 /$ belgeo. 11216

ISSN: 2294-9135

\section{Publisher:}

National Committee of Geography of Belgium, Société Royale Belge de Géographie

\section{Printed version}

Date of publication: 30 September 2007

Number of pages: $335-348$

ISSN: 1377-2368

\section{Electronic reference}

Jo Little, «Gender and geography : developments in the United Kingdom 1980-2006», Belgeo [Online],

3 | 2007, Online since 11 December 2013, connection on 22 May 2020. URL : http:// journals.openedition.org/belgeo/11216; DOI : https://doi.org/10.4000/belgeo.11216

This text was automatically generated on 22 May 2020.

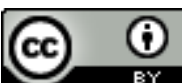

Belgeo est mis à disposition selon les termes de la licence Creative Commons Attribution 4.0 International. 


\section{Gender and geography: developments in the United Kingdom 1980-2006}

Genre et Géographie : Les Développements en Grande-Bretagne, 1980-2006.

Jo Little

\section{Introduction}

1 The purpose of this paper is to outline the progress of feminist geography in the UK over the past 25 years. Not surprisingly, there has been considerable reflection on the development of feminist geography in the UK both as a distinct conceptual approach (or set of approaches) to the study of geography and as a political movement within the discipline. Even while feminist geography was in its relative infancy, papers charting the progress of this academic sub-discipline and placing it in the broader context of the development of UK geography began to be produced (see Bowlby et al., 1989 ; McDowell, 1993; WGSG, 1984). Thus many rich texts can be drawn on to inform a review of feminist geography - these have been widely circulated and some have become "classics" within the discipline more generally. The intention, in the first part of this paper, is to reference these earlier books and articles to establish key moments in the development of feminist geography in the UK. In doing so the paper will show how these initial debates laid the foundations of work on gender, establishing new theoretical directions and contesting taken for granted knowledges. It is inevitable that this identification of key moments is selective but the intention is to provide a flavour of the main direction of studies in the UK and not a comprehensive critique.

2 The second part of the paper documents more recent developments in feminist geography in the UK, again selectively. It discusses, in particular, the ways in which geographers have adopted the concept of gender identity enabling them to explore more effectively the differing experiences between and within genders. The paper also shows how work on sexuality and the body has had a growing influence on the 
examination of gender and on the construction and experience of identity. This part of the paper highlights a key shift in the study of feminist geography from examining the constraints operating on particular groups and individuals in particular places, to exploring the co-construction of places and identity in an acknowledgment of the performative nature of gender identity.

In the third section of the paper I attempt to illustrate the main developments in feminist geography in the UK through reference to my own area of research, rural geography. Although not an area noted for its role in driving feminist debates in geography, rural geography has made good use of the increasing legitimacy of work on gender and has drawn on feminist geography to inform the examination of social and economic relations in rural communities and spaces. Again, in the area of rural geography there has been a shift in the focus of feminist approaches; while early work studied the barriers facing women living in rural communities, more recent studies have explored the ways in which gender and rural space are mutually constituted.

Finally, by way of conclusion, the paper briefly situates the place of feminist geography in the UK paying attention to its institutional develop and how it is incorporated within teaching. I acknowledge the important contribution of feminist geography to gender equality in academic work, and in geography in particular. I suggest that early attempts to make women visible in geography as both the subjects of research and as those doing the research were at the heart of the feminist geography project. Recent writing (see Sharp et al., 2004) asserts the need for a continued emphasis on gender equality because, despite considerable change in the position of women geographers, subtle barriers to inclusion and equity still exist for women working in the academy.

\section{Early Feminist Geography in the UK}

It is clearly impossible to pinpoint a precise date or moment when feminist geography "began" in the UK - especially since recognition is rarely given to work that is not published through accepted academic channels. By the mid 1970s, however, a body of work was beginning to emerge in UK geography that looked explicitly at differing gender roles. Such work was part of a growing interest in social geography in the UK and a concern for recognition of the differing experiences of individuals and groups within space. Much of this early work focused on women's lives since it was, as Suzanne MacKenzie $^{1}$ (1984, pp. 3-4) noted, "generally women who experience gender relations as oppressive and constraining". Research explored the daily activities of women, drawing attention to the relationship between inequality of opportunity and the gender division of labour within the household. It argued that geography was dominated by a masculine approach that failed to take seriously the lives of women and failed to acknowledge how daily activities were organised to reinforce gender inequality.

This early focus on gender roles in UK geography cannot be seen in isolation but must be acknowledged as heavily influenced by the feminist movement of the time. Although emphasising the position of women as a neglected group in social scientific analysis, it was underpinned by a broader politics of gender inequality. Thus, it was argued, work sought to show how an understanding of gender was critical to a broader understanding of human-environment relations as a whole. MacKenzie (1984) summarises the three underlying assumptions that shaped (and were shaped by) the development of this initial phase of feminist geography. Firstly, women, in their daily 
lives, enter into social relationships which are different from those of men. Secondly, these relationships mean women have a different experience and perception of the environment than men and, thirdly, these differences are important in understanding the use and development of (urban) space.

Work around these basic assumptions contributed significantly to making women, and their marginalisation, visible. It tended to focus, however, on the ways in which women's activities were spatially constrained as a result of their roles. Such work was later criticised for measuring women against a set of accepted, masculine codes and patterns of behaviour rather than looking at women's particular needs and aspirations for living in and using the city.

8 This focus on the restricted activity spaces of women that characterised very early feminist geography was particularly committed to showing how the problems women faced in their use of the built environment were reinforced by their dual roles. The growing participation of women in paid work meant that many were combining productive and reproductive activity. The separation of home and work, a key feature of urban design and planning in the late nineteenth and twentieth century city, made moving between the spheres time consuming and complicated. Hence, it was argued, women's gender roles were increasingly problematic and constraining. Feminist geographers claimed that insufficient attention had been given to women's experience of the relationship between gender role and urban design and that it was only in drawing attention to such spatial constraints that new priorities for urban development could be advanced. In making these arguments, geographers drew on empirical studies from other disciplines, particularly sociology. They showed how important research on, for example, the experiences of women in the labour market by feminist scholars such as Cockburn (1988) and Beechey (1987) could be used in discussion of the spatial divisions within gendered patterns of employment.

9 Although this work on the spatial restrictions facing women in the operation of their gender roles was undoubtedly valuable and marked the start of an explicit focus on women as a group, it was criticised in two related ways. First it was restricted, essentially, to a spatial framework, highlighting the barriers to women's lives and drawing attention to the way their choices were limited by issues of access and service provision. As such it contributed little to theoretical ideas on the development of urban space. It failed to conceptualise gender as part of the formation of space and place, simply as affected and shaped by it. The second main criticism of this early work was that it was limited to description. Thus it identified the unequal roles of women and men, emphasising the constraints operating on women, yet it did not attempt to go beyond description to explanation. As feminist geography became more established in the 1980s, attention shifted, in an effort to address these criticisms, to considering the social conditions structuring women's social position and to place inequality experienced by women within a broader framework of gender relations.

\section{Patriarchy and the study of gender relations}

Geography and Gender (WGSG, 1984), written collectively by UK women geographers and published in the mid-1980s was a highly significant text that helped to consolidate geographical work on gender roles. Importantly, however, it also shared this concern to move beyond description and to focus on gender relations in order to explain 
unequal gender roles. In so doing it argued that gender relations needed to be seen as a set of power relations between men and women and that women's inequality was the result of the systematic operation of male power over women in all areas of society. Like other geographical work done at the time, Geography and Gender saw that essential to a greater understanding of gender inequality and the gendering of space more broadly was patriarchy, both as a theoretical concept and a set of material practices. In focusing on these broader relations of power at the root of gender inequality, feminist geographers were joining a growing movement within geography concerned with emphasising the structural nature of social relations.

11 Geographers mobilised a wide range of studies to show how patriarchy operated in the "public" sphere of the economy, politics and waged work as well as in the "private" sphere of the home and family. As Bowlby et al. (1989) note, such studies were given added significance by the importance attached to "locality studies" in geographical work at the time in which the interrelations between local and global processes were seen to drive economic and social restructuring. Such studies provided an important opportunity to develop both theoretical understanding and empirical observation of the operation of patriarchy. In particular they raised issues of the relationship between gender and class in discussion of the relative importance of patriarchy and capitalism. This fuelled a debate in which geographers discussed the conceptualisation of the links between gender relations and class (see Foord and Gregson, 1986 ; McDowell, 1986) and sought to define the "necessary and contingent conditions for the existence of patriarchal gender relations" (Bowlby et al., 1989, p. 164). Some argued that patriarchy and capitalism, although linked in social practice, should be seen as conceptually distinct while others believed that the two sets of social relations are intertwined such that they form one system of capitalist patriarchy. The details of the debate are not the concern of this paper, save in demonstrating the interest shown by geographers not only in the material outcomes of patriarchy in terms of gender inequality but also in its theoretical underpinning.

In discussing the nature of patriarchy and its importance in understanding gender inequality, geographers again drew on research from outside geography. Cultural studies literature, for example, provided insights into the city as a site of sexual imagery and control where women's exclusion was related to social expectation around their sexual identity (see, for example, Wilson, 1991 ; 2001). Work from urban studies and planning considered the city as a physical expression of patriarchy showing how the design of urban space reflected male power in terms of both the structure of land use and the emotional response to different parts of the urban environment (Darke, 1996).

13 Increasingly, as work on gender and geography developed in the 1980s, geographers questioned the classic dichotomies that structure western thought. In common with other feminist scholars they started to look at how dichotomies such as mind/body, culture/nature, public/private, reason/emotion are mapped onto gender difference in a way that assumes the inferior of the two attributes to be feminine. As McDowell (1992) notes, the questioning of such phallocentric dichotomies by feminist geographers helped to reveal how the feminine has been constructed as "natural" and, as such, excluded from theorising. Breaking down the idea of the feminine as natural turned attention away from the idea that gender differences were biologically fixed and 
towards the recognition that they reflect socially constructed notions of masculinity and femininity.

\section{Gender Identities}

As work on the social construction of masculinity and femininity took hold within UK geography, the focus of research shifted from discussion of grand theory to the recognition and examination of difference. This shift was again part of a wider move in the discipline in the UK in response to postmodern and poststructural influences (see Pile and Thrift, 1995). The notion of gender identity increasingly replaced gender relations and roles in suggesting that characteristics of masculinity and femininity are not fixed or essential but are culturally constructed and change over time and space. While subject to social regulation, identities are more open to choice and to defining individual's sense of self. Moreover, as Jackson (1999, pp. 132-133) points out :

"Whereas older theories of identity posited a stable and core sense of self, often closely tied to differences of social class, recent theories have asserted the possibilities and problems associated with more 'hybrid' (unstable, mixed and multiple) notions of identity, often conceptualised in highly voluntaristic terms as part of an individual 'lifestyle' choice".

It was only through looking at identity, feminist geographers argued, that the complex and diffuse nature of gender could be appreciated. In drawing attention to the multiplicity and fluidity of gender identity it was recognised, in addition, that feminist research in geography could no longer rest on a single unproblematized concept of patriarchy but needed to incorporate a complex set of gender relations which varied over time and place (McDowell, 1992).

Thus feminist geographers started to move away from the study of women as an "undifferentiated category" (McDowell, 1993) to think about the social dimensions that divide women. They focused on how the characteristics of masculinity and femininity varied between different classes, "races", ethnicities, sexualities and ages and on how such characteristics were spatialised. An impressive number of studies from across the discipline drawing attention to the localised and individual experiences of gender identity were (and continue to be) produced. In these studies the differences amongst women and amongst men became as important as those between men and women.

This direction in UK feminist geography was strongly influenced by feminist studies generally with influences not only from the UK but also from the US and Australia in particular. Perhaps more significantly, shifts in the direction of feminist geography were very much informed by the wider feminist political movement. By the 1990s fundamental questions were being asked about the "audience" for feminist scholarship and activism. Concerns that the feminist movement was failing to address the particular circumstances of women of colour and non-western women were reinforced by an attack on white women working in the academy who were seen, by elements of the feminist movement, as part of the problem of inequality and exclusion rather than part of the solution (McDowell, 1993). Questions started to be asked about the claims of feminist scholarship and, in particular, how relevant theoretical debates about the nature of women's oppression and the operation of patriarchy, were in understanding the multiple divisions between different identities. 

the diversity of gendered experiences; it challenged the salience of gender as an analytical category. By suggesting that identities were fractured, partial, decentred and shifting, feminists had successfully argued that the experience of gender was not uniform and could not be "read off" according to a set of universal characteristics and power relations. While this was extremely helpful in broadening the understanding of women's inequality, it potentially undermined the importance of gender both as a theoretical concept and as a basis for empirical observation and experience. Thus as Linda McDowell wrote in 1992 (p. 412):

"One of the consequences of the recognition of differences between women has been the development of what Susan Bordo (1990) has termed 'gender scepticism' (p. 125)".

She goes on to argue that one of the consequences of such gender scepticism was that the idea of a single feminism was untenable and should be replaced by multiple feminisms in which theories are built around particular circumstances and political alliances around specific issues. Similarly, Liz Bondi (2004) recognises the inherent contradiction for feminist politics of difference and while arguing that acknowledging a multiplicity of gender identities requires us to think differently about the universal tendencies of feminist theory, warns of the dangers of fragmentation.

Geographers in the UK have debated the continuing relevance of gender in the context of studying multiple identities and have remained positive about the focus on difference. There has been a broad recognition of notions of difference and the study of multiple subjectivities as empowering rather than disabling, helping to animate the field of feminist studies in various ways. Bondi (2004) notes how the study of processes and outcomes over space has long brought geographers into contact not only with the fractured nature of gender but with the need to build alliances. Geographers are wellplaced to help ensure that these alliances take place over space and that negotiation takes place around "different differences". In doing so, Bondi (2004, p. 11) warns of the importance of being open to possibilities and seeing space as "neither gender-free nor gender-saturated".

\section{Feminist geography and embodiment}

With the focus on difference and deconstruction, feminist geography in the UK has increasingly turned its attention to the body and to the performative nature of gender identity. Again, such work cannot be discussed without acknowledging its links to wider debates in geography (see Dewsbury, 2000; Thrift, 2007) or on the work of theorists beyond the confines of UK geography, such as Judith Butler (1990) and Elizabeth Grosz (1994). In recognising that gender categories are not fixed or universal, greater emphasis has been placed by feminist scholars on the ways in which gender is constructed and performed in different places at different times. This focus on the performative nature of identity has foregrounded the body, arguing that it is embodied acts of repetition and style through which our identities are created and reproduced.

These theoretical discussions within feminist geography have encouraged a host of studies on the embodied experience of gender identity. In these studies geographers have explored the materiality of the body, showing how constructions of masculinity and femininity are etched on to and shaped by embodied performance. The body has 
been seen, increasingly, by geographers as central to understandings of a range of topics such as consumption, mobility, disability and health. In addition, ideas about the body and expectations surrounding the body have been seen as important in understanding the ways in which we experience and value different places. Work on the body has been used, specifically, to further break down established binaries which associate the body with nature, femininity and emotion and as such in opposition to masculinity, rationality, science and the mind.

Where bodies have been seen as particularly relevant to geographical enquiry is in work on sexual identity. Early work on gender from feminist geographers constantly fought to show how gender was socially constructed and not a function of physical or biological difference between men and women. In striving to emphasise the importance of gender as a social construct, however, the sexual tended to be incorporated with the physical and, consequently downplayed. As Bondi (1997) summed up :

"While the expressed intention of the sex/gender distinction widely adopted in feminist urban studies has been to exclude questions of biological sex to make the point that gender divisions are socially constructed, one of the effects has been to exclude questions of sex in the sense of sexuality and sexual practice... Thus despite the feminist claim that the personal is political, and despite the feminist critique of the public/private dichotomy... we have largely avoided matters regarded as personal or private".

In striving to disconnect the body from the physical characteristics of gender identity, biology has thus been relegated in favour of a focus on the social. Yet recently there have been calls for studies of the body to pay more attention to the biological particularly in relation to debates around the relationship between the body and nature. The notion of the lived body has emerged as potentially useful in bringing together social and physical analyses of the gendered body.

The focus on the body has provided an important encouragement for studies of sexuality by feminist geographers. The emphasis of work has been to show how sexual identity is separate from gender identity and that, like gender, it is socially constructed. Geographers have again drawn on the work of feminist theorists on the body in exploring how the sexed body is incorporated in the performance of identity and how it is regulated and controlled in accordance with the hegemonic power of heterosexuality.

As with writing on the body, a rich and diverse collection of studies now exists on geographies of sexuality in the UK. Such work has highlighted the marginalisation of "different" sexualities in particular spaces and attempted to show how sexual identity is performed, contested and disciplined through the body in different spatial contexts. The work of geographers such as Hubbard (2000) and Kitchin (Kitchin \& Lysaght, 2003) has shown how a "moral geography" has shaped the relationship between sexual identity and space in defining acceptable and unacceptable practices and regulating sexual activity. They, and others, discuss, how this renders particular bodies "out of place" in particular spaces and times. They also show how this regulation of sexual identity goes beyond a homosexual/heterosexual division to control any form of sexual practice that does not conform to a family-based hetero-normalcy.

The body has also been seen, importantly, by feminist geographers as a site for the contestation of sexual and gender identity. Studies have looked at the ways in which the body is used to destabilise assumptions about the relationship between sexuality and space and to take control of different spaces for "non-traditional" and 
marginalized identities. Such work has focused on spaces of leisure and the street in particular, looking at how such spaces become the sites of public displays of homosexuality at certain times (see for example Hubbard and Sanders, 2003 ; Kitchin and Lysaght, 2003 ; Valentine, 1993 ; 1996). In describing the way in which the space is destabilised as a heterosexual space, geographers seek to emphasise how places are constantly in the process of becoming; they are not fixed but are made and remade through the negotiation of power relations and the expression of different identities.

The performative approaches adopted by feminist geographers have incorporated a growing emphasis on work on emotions. Still in its infancy, such research is already having a significant impact on the nature of topics studied and the value placed on understanding varying ways of experiencing space and place. Study of emotional geographies is part of a movement to show how the co-construction of place and identity incorporates a range of different influences (for example memory, sense, faith and belief) not previously given much attention by geographers.

This outline of feminist geography in the UK has, by necessity, been wide ranging and rather superficial but it has tried to indicate the various key "phases" of development in academic approaches to the study of gender. While it has implied a sequential replacement of one phase by another, in reality different approaches have merged together and co-existed. For example, despite the recent recognition of gender identity and its fluidity, some current research continues to identify changes in gender roles and to assert the continued relevance of patriarchy. One way of showing the development of approaches to feminist geography is to look at a particular area of geography. Here I use rural geography to illustrate the ways in which feminist geography has been adapted through the different phases of its development. The discussion charts the shift from early work on rural gender roles and the introduction of feminist perspectives to rural geography, through a focus on gender relations and patriarchy to recent examination of gender identity, the body and sexuality in rural areas.

\section{Feminist Rural Geography}

Reference to rural gender issues and, in particular, women's roles, first emerged through work on agriculture and the family farm. While not adopting an explicitly feminist theoretical framework, this research drew attention to unequal gender roles within agriculture and the routine under valuing of women's contribution to the farm business (see, for example, Gasson, 1992; Whatmore, 1991; Whatmore et al., 1994). Interest was stimulated initially through attention to the family farm as an example of petty commodity production and the particular position of family labour as an aspect of capitalist labour relations. It was argued that many farm businesses were only viable because of the reliance on family labour and the business could survive without being subject to labour costs. As part of this analysis, feminists began to draw particular attention to the lack of recognition of women's work. They showed how women's labour was critical to the survival of the family farm both in terms of the agricultural work and domestic reproduction (Shortall, 1992 ; Symes and Marsden, 1983). Debates around the work of women on the farm were used, importantly, to show how the spheres of production and reproduction were intricately linked and argued that 
women's domestic work was as valuable to the productive work on the farm as their agricultural activity (Evans and Ilbery, 1992).

Following this initial exploration of women's roles in agriculture, studies of gender roles in other areas of rural community and society began to be produced (see Little, 1986; Middleton, 1986; Stebbing, 1984). In common with directions in feminist geography at the time, such work sought to "add women in" to existing rural studies, highlighting where male and female roles in rural areas differed. Again, the emphasis of this early phase was about making rural women visible and showing how existing research had neglected their activities, needs and interests. Much of the work focused on employment and service provision and argued that rural women were subject to a "dual burden" in that they were excluded from employment and access to services as a result of both their gender and their location. The disadvantage faced by women (in, for example, access to employment opportunity) as a result of their gender role was seen to be reinforced by the conditions of rurality, in particular the lack of services and low levels of transport (see Halliday, 1997 ; Little, 1991).

The examination of different gender roles and the recognition of women's dual burden in rural areas was, like in the study of feminist geography generally, followed by calls for explanation and for theoretical attention to gender relations. In response, research on rural gender began to incorporate an understanding of power relations, including the operation of patriarchy, showing how unequal gender roles were the outcome of a set of power relations between men and women in the domestic sphere and in the world of waged work. How these power relations were played out amongst men and women were examined in both farming and non-farming environments. Patriarchal power was seen as the basis of women's inequality and also responsible for exposing women to the more problematic aspects of rural life - in particular the lack of opportunity in terms of childcare, services and employment (Little, 1987).

While drawing on broad theories of gender inequality, those studying rural gender issues also stressed the spatial basis of power relations and the particular implications of rurality. Thus they sought to make it clear that patriarchy, as a global process, shaped rural women and men's lives as it did the lives of women and men in general. But they also argued that patriarchy took a particular form in rural areas and communities that made the operation of gender relations in these areas potentially different from those taking place elsewhere. They stressed, in particular, that rural society and community placed a powerful set of expectations and assumptions on women in relation to the operation of their gender role. Rural women, it was argued, were subject to much more conventional gender relations due to the overwhelmingly conservative and traditional nature of rural society. Pressures to conform to classic gender roles were part of a rural patriarchy that remained largely uncontested in rural communities.

34 A significant body of research published in UK rural geography during the 1990s showed how rural women were subject to strong "cultures of domesticity" (Hughes, 1997) and how, as such, they occupied an important place in the centre of the family and rural domestic life (Little, 1997). This domestic role was also seen to spill out into the community as part of the accepted role of rural women was as the "lynch pins" of the community, both practically and ideologically. Studies argued that pressure to conform to the domestic and community based roles had implications for rural women's participation in the labour market. Such pressures, combined with the 
practical difficulties of living in remote(r) environments restricted their employment and further reinforced their roles in the private spheres of home and community.

Following the development of feminist geography generally, recent studies of rural gender has focused more directly on the construction and performance of identity. The cultural turn in geography stimulated research on rural gender in two important ways - empirically in the exploration of rural women as a "neglected other" (Philo, 1992) and theoretically in discussions around the relationship between cultural constructions of rurality and gender identities. Both are ongoing areas of enquiry and have provided important contributions to understanding both the day to day experiences of rural women and men and to the ways in which concepts of rurality and gender can be articulated in a cultural context. Again, one of the key directions of this work is to show how ideas of rurality are folded into the ways in which gender identities are made and remade on a daily basis. Recognition has been given to the varying and multiple ways in which this relationship develops in different places amongst different individuals and groups. Geographers have also stressed the co-construction of rurality and gender, suggesting that the two are constantly negotiated in the way they come together in specific cases.

In looking at the construction of rural gender identities, geographers have started to engage with ideas on embodiment. Some interesting work on rural masculinity has shown how conventional assumptions about the male body continue to dominate in rural areas, particularly in an agricultural context. Authors such as Brandth (1995) and Saugeres (2002) have shown how representations of farmers emphasise a traditional masculinity that celebrates the fit, healthy and powerful body. They argue that such embodied forms of masculinity carry with them associations of broader skills and competences, thus making the link between the body and gender identity. Recently studies of the rural body have been developed to include a greater consideration of sexual identity, suggesting that more traditional ideas towards the body reflect and are shaped by the dominance of a very conventional form of hetero-normalcy (see Little, 2003). This, it is argued, is rooted in a conservative construction of rurality that has at its centre the nuclear family and associated heterosexual gender identities. Work on the body and sexual identity by rural geographers is, however, in its relative infancy and remains a rich area for future research and writing.

\section{Placing Feminist Geography}

The preceding sections of this paper have provided a brief history of the development of feminist geography in the UK and of work on gender in geography more broadly. It has not of course been comprehensive but has attempted to pick out the key areas of debate and to show how theoretical understanding has unfolded in line with both geography and women's studies. The case of rural geography has been used to illustrate how the different theoretical "phases" of feminist geography have influenced the content and direction of one sub-disciplinary area. The task of this final part of the paper is to talk about the relationship between feminist geography as an academic area of study and as a political direction within the academy. In so doing the main focus is on the way feminist geography has been communicated through teaching.

Perhaps the most striking point to note about the teaching of feminist geography in the UK over the past 25 years is the major shift in attitudes towards its acceptability. 
Feminist geography has, over this time, moved from the margins of the subject to, if not quite the centre, then at least the mainstream. It is now a legitimate area of research and teaching and, moreover, its development is generally included as an element in courses on the development of concepts in human geography. Further, feminist geography today, it may be argued, is less often ghettoised in teaching, increasingly seen as broadly relevant to a range of topic areas and not simply taught in specialist courses on gender. While acknowledging that the teaching of feminist geography has come a long way since the early battles over legitimacy, Sharp et al. (2004), writing in a recent Women and Geography Study Group publication, warn of the dangers of complacency and of the need to keep drawing attention to gender issues both as an area of study and as a feature of the institutional base of the discipline.

Perhaps rather strangely I have not mentioned the contribution and influence of the Women and Geography Study Group (WGSG) of the Institute of British Geographers (now the Royal Geographical Society/IBG) in my earlier discussion of the development of feminist geography in the UK. It is important to recognise, however, that the way the subject emerged and developed to contribute in such a powerful way to UK geography was due, in no small part, to the WGSG. This group, which began as a very small and informal collection of women scattered through British academia, acted (and continues to act) as an important source of contact for those interested in drawing attention to gender issues in geography. It provided a forum for debate and for writing (the results of which are some well-known and important publications - see WGSG, 1984; 2004 ; Laurie et al., 1997) and as a mark of institutional acceptability at a time when many of the ideas being put forward were seen as at best irrelevant and at worst unacceptable in some geography departments. The WGSG has not remained static but has evolved as the pressures on feminist studies in geography have changed, it remains, however, an important source of support for those researching and teaching feminist geography in the UK and overseas.

One of the key issues that has accompanied the increasing visibility of feminist geography in research and teaching is the development of feminist methodologies. Again, space has not allowed me to pay much attention to this issue although it should be mentioned here as playing a particular part in teaching feminist geography. Feminist geographers have sought, throughout the development of work on gender issues, to encourage debate on and adoption of more qualitative research methods these they see as a crucial tool in research that is more centred on the individual and the household and which seeks to explore questions of experience and lifestyle. Coupled with the use of these qualitative methods is a concern for the positionality of both researcher and researched. Feminist methodologies stress the ethical responsibilities of the researcher and acknowledge the power relations inherent in the research process. They take seriously the need to include the research subject in the design of research and to make research findings available to those who have been active in its production. Methodology has become a rich area of writing and publishing within feminist studies and one that is seen to cross the borders between human and physical geography (McDowell, 1992 ; Pain, 2004 ; Sharp, 2005).

41 It is not possible to end a paper like this without drawing attention to the vast distances covered by feminist geography in the UK over the last 25 years. Here I have not been able to do justice to more than a very small fraction of the work that has formed part of this movement. My intention was to convey something of its diversity 
and of the progress that has been made in theoretical understanding of gender issues and feminist geography. That examples of feminist work can now be found throughout different parts of UK geography is testimony to the strides that have been made in asserting its relevance and contribution. Clearly, such a move must be seen within the broader context of the development of feminist studies generally and of geography in the UK.

From the early concerns for social inequalities to the more recent emphasis on performance and emotion, geography itself has developed in a way that has allowed feminist work to flourish. In particular the increasing attention given to difference with the postmodern turn has ensured that the question of gender continues to be taken seriously and research remains committed to highlighting the local, everyday experiences of men and women within all sorts of spatial contexts. Feminist geography must also take some credit for the interest in local expressions of difference and inequality and its influence has surely extended beyond the boundaries of specific work on gender. This paper may incite criticism for its unflinchingly positive reflection. of course, within the history I have described there have been battles and setbacks as well as concerns at times about the direction of feminist geography. There still remains an imbalance in terms of membership of the academy with fewer women than men becoming lecturers and attaining the more senior roles. Despite these more negative points, however, I defend the positive stance I have taken in recognition of not only the rich work that has existed to date but also the promise for the future.

\section{BIBLIOGRAPHY}

BEECHEY V. (1987), Unequal Work, London,Verso.

BONDI L. (2004), “ $10^{\text {th }}$ Anniversary address for a feminist geography of ambivalence", Gender, Place and Culture, 11, pp. 3-15.

BONDI L. (1997), "Sexing the city”, in FINCHER R. and JACOBS J. (eds.), Cities of Difference, New York.,Guilford Press.

BOWLBY S., LEWIS J., McDOWELL L. and FOORD J. (1989), “The Geography of Gender”, in PEET AND THRIFT (eds.), New Models in Geography, 2, London, Unwin Hyman.

BRANDTH B. (1995), "Rural masculinity in transition : gender images in tractor advertisements", Journal of Rural Studies, 11, pp. 123-133.

BUTLER J. (1990), Gender Trouble, London, Routledge.

COCKBURN C. (1988), "The gendering of jobs : workplace relations and the reproduction of sex segregation", in WALBY S. (ed.), Gender Segregation at Work, Milton Keynes, Open University Press. DARKE J. (1996), “The man-shaped city”, in BOOTH C., DARKE J., and YEANDLE S. (eds.), Changing Places : women's lives in the city, London,Paul Chapman.

DEWSBURY J.D. (2000), "Performativity and the event : enacting a philosophy of difference", Environment and Planning D : Society and Space, 18, pp. 473-496. 
EVANS N. and ILBERY B. (1996), "Exploring the influence of farm-based pluriactivity on gender relations in capitalist agriculture", Sociologia Ruralis, 36, pp. 74-92.

FOORD J. and GREGSON N. (1986), “Patriarchy : towards a reconceptualisation”, Antipode, 18, pp. 186-211.

GASSON R. (1992), "Farmers' wives and their contribution to the farm business", Journal of Agricultural Economics, 43, pp. 74-87.

GROSZ E. (1994), Volatile Bodies : Towards a Corporeal Feminism, Bloomington, Indiana University Press.

HALLIDA J. (1997), “Children's services and care : a rural view”, Geoforum, 28, pp. 103-119.

HUBBARD P. and SANDERS T. (2003), "Making space for sex work : female street prostitution and the production of urban space", International Journal of Urban and Regional Research, 27, pp. 75-89.

HUGHES A. (1997), "Rurality and cultures of womanhood : domestic identities and moral order in rural life", in CLOKE P. and LITTLE J. (eds.), Contested Countryside Cultures, London, Routedge.

JACKSON P. (1999), "Identity”, Entry in Feminist Glossary of Human Geography, Londond, Arnold.

KITCHIN R. and LYSAGHT K. (2003), "Heterosexism and the geographies of everyday life in Belfast, Northern Ireland", Environment and Planning A, 35, pp. 489-510.

LAURIE N., DWYER C., HOLLOWAY S. and SMITH F. (eds.) (1999), Geographies of New Femininities, London,Longman.

LITTLE J. (1986), “Feminist perspectives in rural geography : an introduction”. Journal of Rural Studies, 2, pp. 1-8.

LITTLE J. (1987), “Gender relations in rural areas : the importance of women's domestic role”, Journal of Rural Studies, 3, pp. 335-42.

LITTLE J. (1991), "Women and the rural labour market : a policy evaluation", in CHAMPION T. and WATKINS C. (eds.), People in the Countryside: Studies of Social Change in Rural Britain, London, Paul Chapman.

LITTLE J. (1997), “Employment, marginality and women's self-identity", in CLOKE P. and LITTLE J. (eds.), Contested Countryside Cultures: Otherness, Marginalisation and Rurality, London, Routledge.

LITTLE J. (2003), “'Riding the rural love train' : heterosexuality and the rural community", Sociologia Ruralis, 43, pp. 401-417.

McKENZIE S. (1984), “Editorial”, Antipode, 16, pp. 3-9.

McDOWELL L. (1986), “Beyond patriarchy : a class-based explanation of women's subordination”, Antipode, 18, pp. 311-321.

MCDOWELL L. (1992), “Doing gender : feminism, feminists and research methods in human geography", Transactions of the Institute of British Geographers, NS, 17, pp. 399-416.

MCDOWELL L. (1993), "Space, place and gender relations : Part 2. Identity, difference, feminist geometries and geographies", Progress in Human Geography, 17, pp. 305-318.

MIDDLETON A. (1986), “Marking boundaries : men's space and women's space in a Yorkshire village", in LOWE P., BRADLEY T. and WRIGHT S. (eds.), Deprivation and Welfare in Rural Areas, Norwich, Geo Books.

PAIN R. (2004), “Social geography : participatory research”, Progress in Human Geography, 28, pp. 652-663. 
PHILO C. (1992), “Neglected Rural Geographies : a review”, Journal of Rural Studies, 8, pp. 193-207.

PILE S. and THRIFT N. (1995), Mapping the Subject : Geographies of Cultural Transformation, London, Routledge.

SAUGERES L. (2002), "The cultural representation of the farming landscape : masculinity, power and nature", Journal of Rural Studies, 18, pp. 373-404.

SHARP J. (2005), "Geography and gender : feminist methodologies in collaboration and in the field”, Progress in Human Geography, 29, pp. 304-209.

SHARP J., BROWNE K. and THIEN D. (2004), "Preface", Geography and Gender Reconsidered, CD, Women and Geography Study Group, Royal Geographical Society (with the Institute of British Geographers).

SHORTALL S. (1992), "Power analysis and farm wives : an empirical study of the power relations affecting women on Irish farms", Sociologia Ruralis, 32, pp. 431-51.

STEBBING S. (1984), “Women's roles and rural society”, in BRADLEY R. \& LOWE P. (eds.), Locality and Rurality : Economy and Society in Rural Regions, Norwich, Geo Books.

SYMES D. and MARSDEN T. (1983), “Complementary roles and asymmetrical lives : farmers' wives in a large farm environment”, Sociologia Ruralis, 23, pp. 229-41.

THRIFT N. (2007), Non-representational Theory : Space, Politics, Affect, London, Routledge.

VALENTINE G. (1993), “(Hetero)sexing space : lesbian perceptions and experiences of everyday spaces", Environment and Planning D : Society and Space, 11, pp. 395-413

VALENTINE G. (1996), "Renegotiating the heterosexual street : lesbian productions of space", in DUNCAN N. (ed.), Body Space, New York, Routledge.

WHATMORE S. (1991), Farming Women : gender work and family labour, Baskingstoke, Macmillan.

WHATMORE S., MARSDEN T. and LOWE P. (eds.) (1994), Gender and Rurality, London, David Fulton.

WILSON E. (1991), The Sphinx in the City : urban life, the control of disorder, and women, London, Verso.

WILSON E. (2001), The contradictions of culture: Cities, culture, women, London, Sage.

WOMEN AND GEOGRAPHY STUDY GROUP (1984), Geography and Gender, London, Hutchinson.

WOMEN AND GEOGRAPHY STUDY GROUP (2004), Geography and Gender Reconsidered, CD, Women and Geography Study Group, Royal Geographical Society (with the Institute of British Geographers).

\section{NOTES}

1. Suzanne MacKenzie was a Canadian feminist geographer who was based in the UK for her PhD and whose work became an important part of the early development of UK gender and geography debates. 


\section{ABSTRACTS}

This paper outlines the progress of feminist geography in the UK over the past 25 years, drawing on just some of the rich texts that have been produced. It charts the development of the subdiscipline through the key theoretical shifts. Within this discussion it pays particular attention to recent developments in feminist geography in the UK. It examines the ways in which geographers have adopted the concept of gender identity enabling them to explore more effectively the differing experiences between and within genders. The paper also shows how work on sexuality and the body has had a growing influence on the study of gender and on the construction and experience of identity. Using the example of rural geography, the paper goes on to explore how feminist approaches have influenced a particular sub-area of geography over the past 30 years. The paper ends by asserting that while there is much to celebrate in the development of feminist geography in the UK, there is still a need for a continued emphasis on gender equality.

Cet article trace le développement de la géographie féministe en Grande-Bretagne ces 25 dernières années, en s'appuyant sur un nombre de textes significatifs. Il montre l'évolution de la sous-discipline à travers des avancées théoriques majeures et met en évidence la façon dont les géographes anglais ont adopté le concept d'identité de genre. Cela leur a permis d'explorer plus efficacement les différentes expériences entre et parmi les genres. L'article démontre comment des recherches sur la sexualité et les corps ont influencé l'étude de genre ainsi que la construction et l'expérience d'identité. L'exemple de la géographie rurale sert à montrer comment des approches féministes ont fait évoluer la géographie humaine ces 30 dernières années. L'article se termine avec un mot de caution. Bien que la croissance de la géographie féministe en Grande-Bretagne soit à célébrer, le besoin d'insister sur l'égalité de genres est toujours présent.

\section{INDEX}

Mots-clés: dévelopement théorique, identité, géographie rurale

Keywords: theoretical development, identity, rural geography

\section{AUTHOR}

\section{JO LITTLE}

Department of Geography, University of Exeter, jklittle@exeter.ac.uk 